\title{
Diagnostics for studying deposition and erosion processes in JET
}

\author{
J.P. Coad ${ }^{\mathrm{a}, *}$, H.-G. Esser ${ }^{\mathrm{b}}$, J. Likonen ${ }^{\mathrm{c}}$, M. Mayer ${ }^{\mathrm{d}}$, G. Neill ${ }^{\mathrm{a}}$, \\ V. Philipps ${ }^{\mathrm{b}}$, M. Rubel ${ }^{\mathrm{e}}$, J. Vince ${ }^{\mathrm{a}}$, \\ JET EFDA Contributors ${ }^{1}$ \\ ${ }^{\text {a }}$ EURATOM/UKAEA Fusion Association, Culham Science Centre, Abingdon, Oxon OX14 3DB, UK \\ ${ }^{\mathrm{b}}$ Association EURATOM-Forschungszentrum Jülich, IPP, D-52425 Jülich, Germany \\ ${ }^{c}$ VTT Processes, Association EURATOM-TEKES, P.O. Box 1608, 02044 VTT, Finland \\ d Max-Planck Institut für Plasmaphysik, EURATOM Association, Boltzmannstr 2, D-85748 Garching, Germany \\ e Alfvén Laboratory, Royal Institute of Technology, Association EURATOM-VR, 10044 Stockholm, Sweden
}

Available online 25 August 2005

\begin{abstract}
Estimates of erosion, deposition and H-isotope retention in JET from previous divertor campaigns have relied on analysis of in-vessel components removed at shutdowns. The components analysed have also provided an incomplete coverage of the vessel. In 2004, new diagnostics are being installed to give a more complete picture (such as smart tiles) and to provide some time resolution. The latter includes further quartz microbalances (QMB), following the successful operation of a prototype in 2002-2004 [H.-G. Esser, G. Neill, P. Coad, G.F. Matthews, D. Jolovic, D. Wilson, M. Freisinger, V. Philipps, Quartz microbalance: a time-resolved diagnostic to measure material deposition in JET, Fusion Eng. Des. $66-68$ (2003) 855-860; H.-G. Esser, V. Philipps, M. Freisinger, G.F. Matthews, J.P. Coad, G.F. Neill, JET EFDA Contributors, Effect of plasma configuration on carbon migration measured in the inner divertor of JET using quartz microbalance, J. Nucl. Mater. 337-339 (2005) 84-87], which will also have temperature control. Other diagnostics include rotating collectors and deposition monitors [M. Mayer, V. Rohde, P. Coad, P. Wienhold, ASDEX Upgrade Team, JET EFDA Contributors, Carbon erosion and migration in fusion devices, Phys. Scr. T111 (2004) 55-59]. Units are also being installed to provide information on mirrors for ITER.
\end{abstract}

(C) 2005 Elsevier B.V. All rights reserved.

Keywords: Diagnostics; Divertor; Tokamak; Retention

\footnotetext{
* Corresponding author. Tel.: +44 1235464 478; fax: +44 1235464554 .

E-mail address: paul.coad@jet.uk (J.P. Coad).

1 See annexure of J. Pamela et al., Fusion Energy 2002, Proceedings of 19th International Conference, Lyon, IAEA, Vienna, 2002.
}

\section{Introduction}

Information on how and where tritium (and other hydrogen isotopes) is trapped in JET, is important in understanding the erosion/deposition process well enough to predict performance in ITER. In the 
past, this information has been largely limited to the analysis of first-wall components removed after complete operational campaigns. In the previous campaign (2002-2004), first time-resolved information in JET was obtained using a prototype quartz microbalance (QMB) [1]. More QMBs, together with a range of complementary diagnostics, are being developed for installation in JET in 2004 under the JET Enhancement Programme and Task Force Fusion Technology.

\section{New diagnostics for installation in 2004}

A cross-section of the JET MkII HD divertor being installed in 2004 is shown in Fig. 1. Location A is in the shadowed region at the inner corner of the divertor, with diagnostics viewing radially outward towards the gap between the vertical and floor tiles. Location $\mathrm{B}$ is at the equivalent point in the outer divertor, with diagnostics facing inboard. Location $\mathrm{C}$ is in the new septum replacement structure, with diagnostics viewing inboard towards the inner divertor through slots in the protection tiles.

\subsection{Quartz microbalance}

The prototype QMB worked within the JET divertor for 2 years [1,2], and will be replaced with a similar "standard" one at the same location (A in Fig. 1). Transport and deposition of carbon in JET appears to be a function of temperature, and the rate of deposition measured on the depositing crystal of the QMB may depend on its temperature. Accordingly, two other QMBs are being mounted with sensing crystals in similar positions relative to the louvres to that of the standard QMB. The first of these will be cooled by part of its body being in contact with the inner water-cooled divertor structure. For the second extra QMB, we plan to explore the rate of deposition as the crystal temperature is raised for similar discharges, by incorporating a heater in the design which can heat the crystal up to at least $573 \mathrm{~K}$ ("Heated QMB"). A heated QMB is included at both inner and outer divertors (locations $\mathrm{A}$ and B). Fig. 2 shows the heated QMB sited at the outer divertor. Of course, if the heater is not switched on, the QMB is equivalent to the "standard" one. All the above QMBs are fitted with shutters, so that measurements can be made for a selected part of a pulse. A QMB

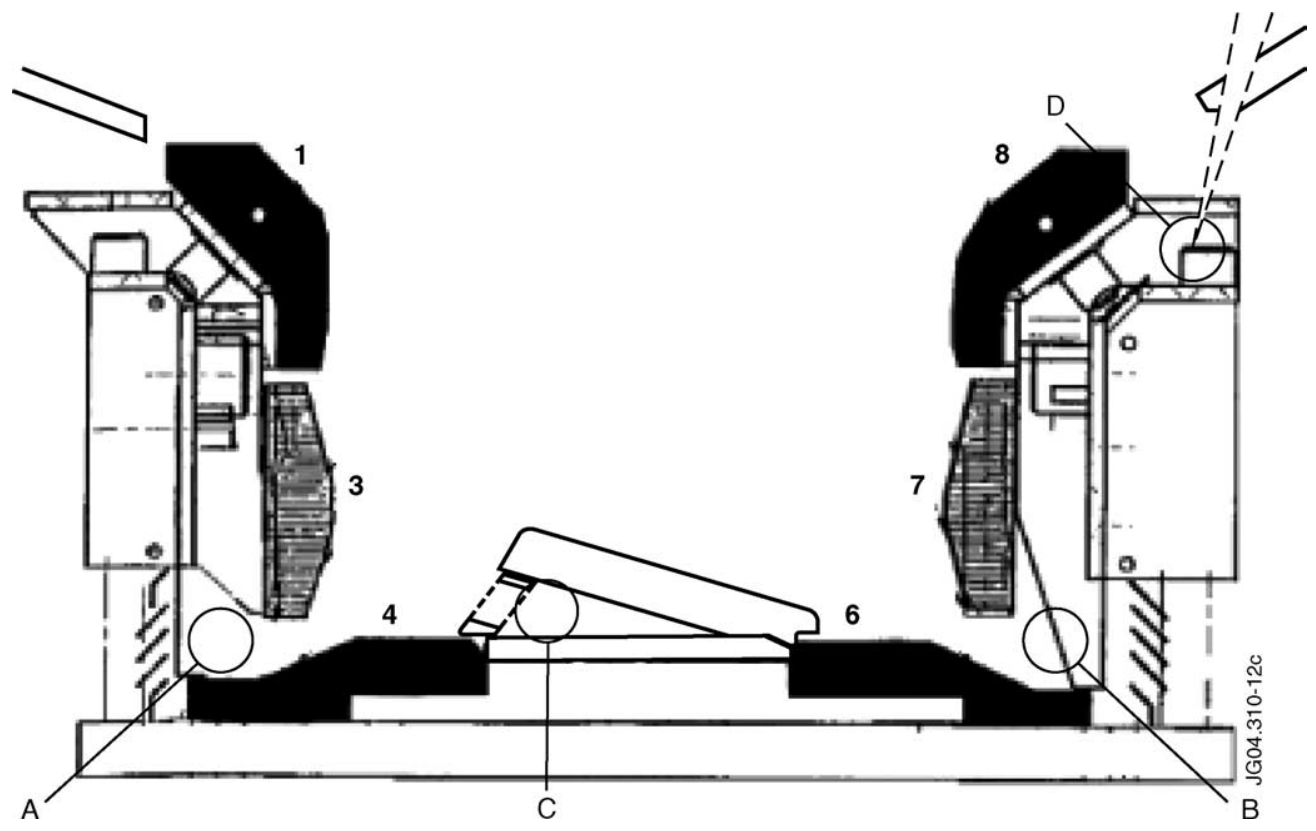

Fig. 1. Cross-section of the JET Mk IIHD divertor that will be in use from 2005 onwards, showing locations of diagnostics for tritium retention studies (A, B, C and D). 


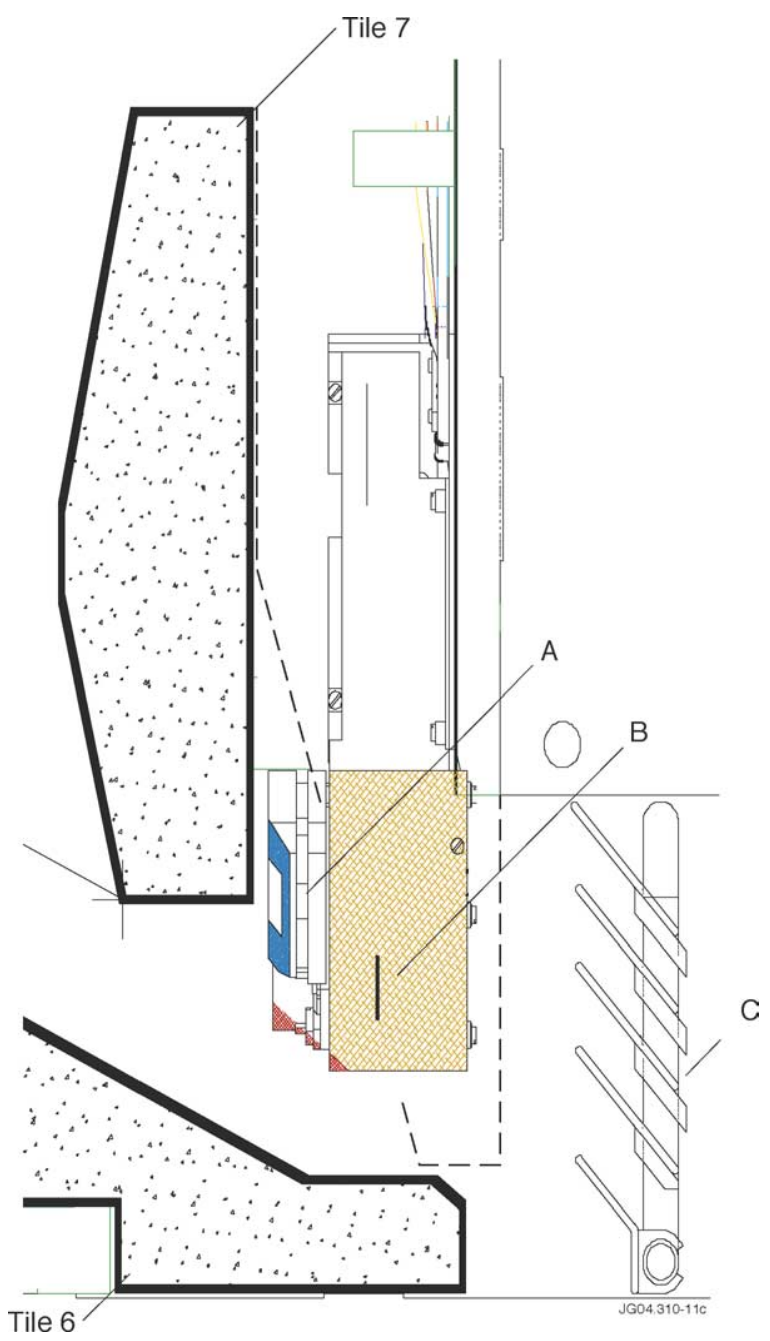

Fig. 2. Cross-section showing the position of the sensing crystal (B) of the heated QMB in front of the louvres $(C)$ at the outer divertor. Exposure time is controlled with a shutter (A).

will also be fitted in the septum replacement structure (location C). There is no room for a shutter, so the QMB crystal will be exposed to all discharges. All the diagnostics at location $\mathrm{C}$ view the inner divertor plasma (and lower target tile) through slots in the CFC protection tiles.

There is also a QMB sited at the top of an outer carrier (location D in Fig. 1). This QMB is designed to monitor the amount of beryllium (Be) evaporated from one of the four evaporator heads in JET. This evaporator is in a similar poloidal plane to the $\mathrm{QMB}$, but near the vessel mid-plane, so it is necessary for the QMB to view through a hole designed in a carbon tile.

\subsection{Rotating collectors}

New collector units are also being developed that have a rotation mechanism powered by the magnetic field. A schematic view of this rotating collector (with the cover removed) is shown in Fig. 3. Every pulse for which the field coils are energised, will advance the first gear by one step. A collector plate that can be easily removed for analysis, fits on the large gear wheel (E), and is exposed through a slot in the end of the case and/or in the cover plate. Erosion/deposition will be monitored over $\sim 3000$ pulses with a time resolution of either 25 or 50 pulses ( 1 or $2 \mathrm{~mm}$ slot width, respectively). Since the units need no electrical connections, they can be fitted to the outer vessel wall in addition to the divertor locations A, B and C. Fig. 4 is a diagram of a wall module which includes a rotating collector (A) and a mirror test unit (B) (see below). This module is to be placed near a Be evaporator, so the collector will collect the Be from that head for each evaporation. Provided there are at least 50 pulses between evaporations, each evaporation will be separately monitored. However, the data on the collectors can only be evaluated after the units are retrieved from the vessel (at a future JET intervention).

\section{Other erosion/deposition diagnostics}

The transport processes involved in deposition in shadowed areas of JET are not understood. First information that most of the hydrocarbon radicals involved have high sticking coefficients, has come from deposition monitors in JET [3]. More deposition monitors will be mounted in 2004 in the new JET divertor (at A, B and C in Fig. 1). Also, louvre clips and sample blocks will be fitted in order to assess easily the amount of deposition on louvres and tile carriers, respectively.

Tests are being conducted in JET aimed at providing information to help predict the likely behaviour of mirrors in ITER. Principle issues are deposition on mirrors in the divertor and erosion of mirrors in the main chamber. Mirror test units (often referred to as "pan pipes" due to their appearance) are being installed 


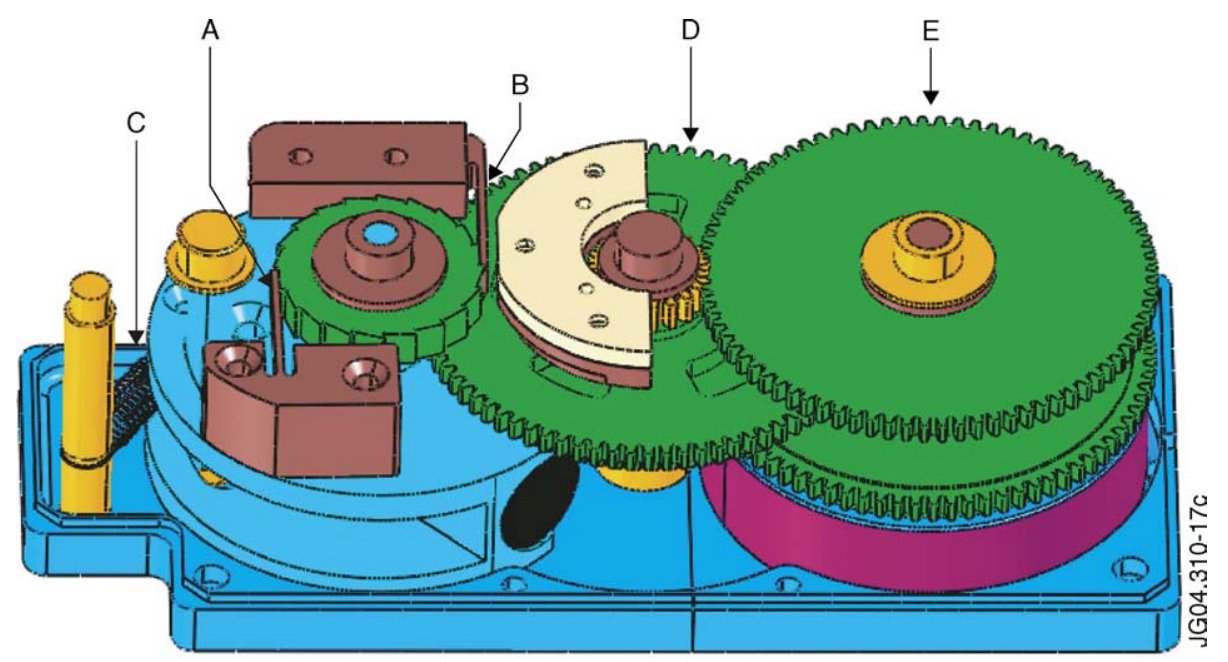

Fig. 3. Diagram of the rotating collector. For clarity, the cover and the collector plate that fits onto the large gear train (E), have been removed. Rotation under the magnetic field is controlled by drive (A), stop (B) pawls and a return spring (C). (D) is an intermediate gear train.

to investigate the effect of aspect ratio for surfaces recessed within slots. The reflectivity of samples of two candidate mirror materials, molybdenum and stainless steel will be determined before and after exposure.

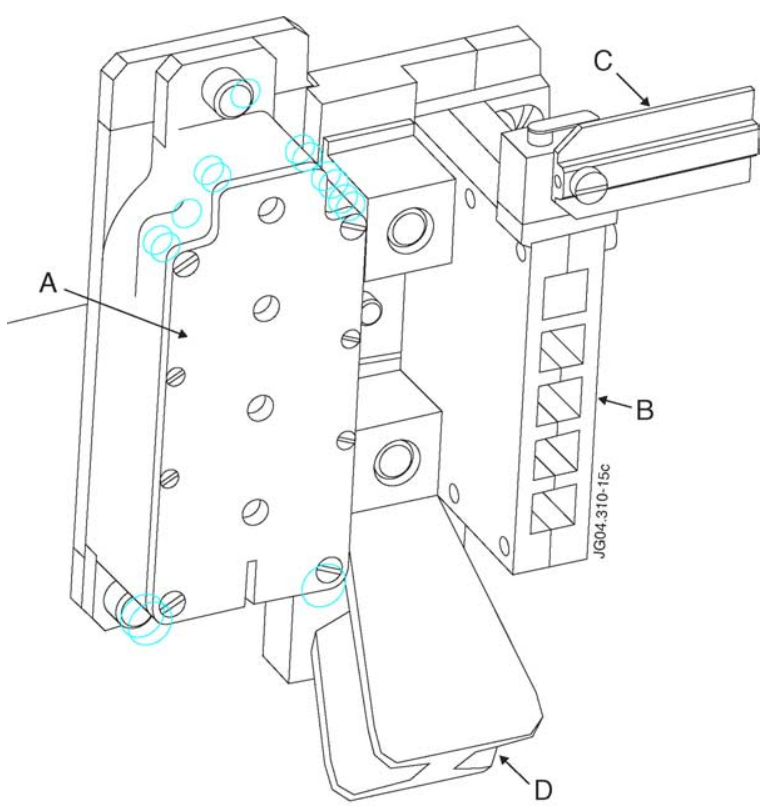

Fig. 4. Unit mounted at the outer mid-plane comprising a rotating collector (A) and a mirror test unit (B). The shutter (C) protects the latter from coating with beryllium during evaporations. (D) is the handle for installation/removal by remote handling.
Information on the effect of temperature on deposition that should come from the QMB measurements will also be relevant. The unit at the outer mid-plane shown in Fig. 4 is fitted with a simple shutter (C) to protect the samples from Be evaporations. Normally the shutter hangs down, covering the samples. However, there is an iron wire in the shutter, and during JET discharges the shutter aligns with the magnetic field (as shown in Fig. 4), thus exposing the samples. This simple device has been used successfully in JET previously.

Fig. 5 is a drawing of the arrangement of diagnostics in one module of the inner divertor. For clarity, the lower set of divertor tiles which come down to the level indicated, and one of the upper set of tiles, are not shown. As can be seen for the QMB in Fig. 2, parts of several diagnostics stand proud of the carrier fins (dashed outline in the figure). Below the lower tiles, it is possible for ions to travel along field lines at a small angle to the toroidal direction into the gap towards the diagnostics, so shielding blocks are fitted to prevent these ions (which are travelling from the right of Fig. 5) striking the diagnostics.

We are interested in quantifying other regions of deposition throughout the torus, and to establish the areas of erosion that act as sources for all the deposition (including at the divertor). Thus, the surfaces of about 30 new "smart" tiles in a poloidal section of the divertor and main chamber are being mapped to an accuracy 


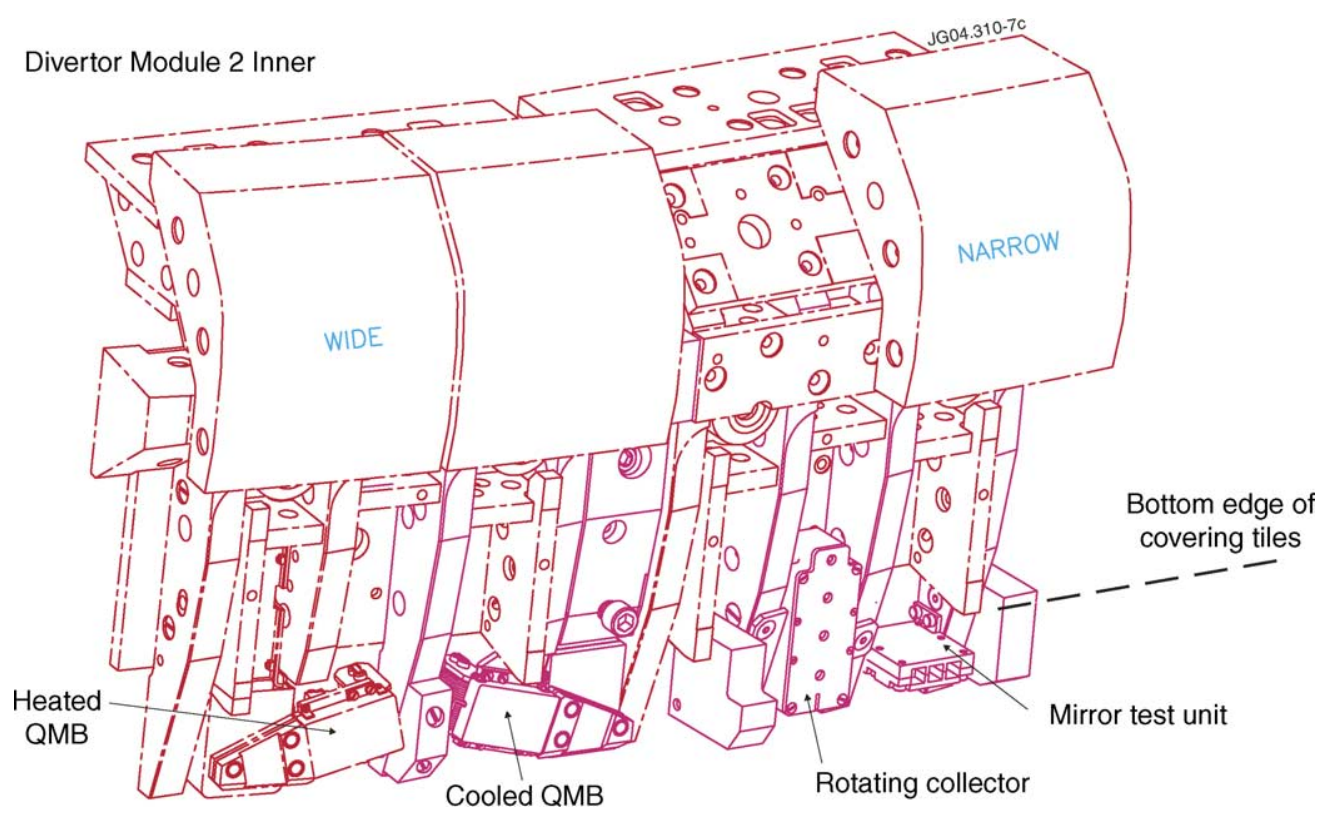

Fig. 5. Drawing of the module 2 inner divertor carriers showing the positions of diagnostics. The lower set of divertor tiles are not shown (nor one of the upper tiles).

of $\sim 5 \mu \mathrm{m}$ in the laboratory, most of which are also being coated with stripes of tungsten and carbon. Remeasurement after exposure in JET, will determine the erosion/deposition pattern in a more complete manner than has so far been possible.

\section{Conclusions}

In the 2002-2004 JET campaign, a prototype QMB has for the first time given time-resolved information on deposition in the divertor. Apart from replacing this existing QMB, new QMBs are being fitted to the inner divertor to investigate the effect of temperature on deposition rate. QMBs will also monitor Be evaporation and fluxes to the new septum replacement structure.

Rotating collectors are being fitted in various locations in the divertor and at the outer vessel wall. Although they are time-resolving, they cannot be analysed until after they are removed from the torus. Other diagnostics being installed include deposition monitors, samples to measure deposition at the louvres and on tile carriers, and smart tiles to measure erosion/deposition generally around the vessel.
Mirror test units will allow the extent of deposition on, and changes in reflectivity to, samples of mirror materials of interest to ITER to be measured.

\section{Acknowledgements}

This work has been conducted under the European Fusion Development Agreement and is partly funded by EURATOM and the UK Engineering and Physical Sciences Research Council.

\section{References}

[1] H.-G. Esser, G. Neill, P. Coad, G.F. Matthews, D. Jolovic, D. Wilson, M. Freisinger, V. Philipps, Quartz microbalance: a timeresolved diagnostic to measure material deposition in JET, Fusion Eng. Des. 66-68 (2003) 855-860.

[2] H.-G. Esser, V. Philipps, M. Freisinger, G.F. Matthews, J.P. Coad, G.F. Neill, JET EFDA Contributors, Effect of plasma configuration on carbon migration measured in the inner divertor of JET using quartz microbalance, J. Nucl. Mater. 337-339 (2005) 84-87.

[3] M. Mayer, V. Rohde, P. Coad, P. Wienhold, ASDEX Upgrade Team, JET EFDA Contributors, Carbon erosion and migration in fusion devices, Phys. Scr. T111 (2004) 55-59. 